cirrhosis. Both patients have been started on iron chelation and have been clinically stable in the months since their diagnosis.

Our findings are significant for several reasons. First, we do not believe that HPS with cirrhosis secondary to recurrent transfusions in patients with sickle cell anaemia has been previously described. Secondly, given the prevalence of iron overload-induced cirrhosis in patients with sickle cell anaesthesia, as well as the prevalence of HPS in patients with cirrhosis, there are likely to be other undiagnosed cases of HPS in this population. However, the decrease in nitric oxide availability in patients with sickle cell anaesthesia may have a protective effect against the formation of HPS, since elevated nitric oxide levels have been associated with the development of HPS [10]. Thirdly, HPS is not part of the current differential diagnosis of unexplained chronic hypoxaemia in patients with sickle cell anaesthesia. While conditions such as pulmonary venous hypertension, pulmonary arterial hypertension, chronic pulmonary embolism and interstitial lung disease should be first considered, we believe that HPS should also be considered in patients with chronic hypoxaemia. Finally, our report underscores the importance of new therapeutic options that are available to treat chronic iron overload.

\section{Daniel Grinnan*, Alice Herlihy* and Wally R. Smith ${ }^{\#}$}

*Dept of Pulmonary and Critical Care, and "Dept of Internal Medicine, Virginia Commonwealth University Health System, Richmond, VA, USA.

Correspondence: D. Grinnan, Dept of Pulmonary and Critical Care, Virginia Commonwealth University Health System, POB 980050, Richmond, VA 23298, USA. E-mail: dcgrinnan@ vcu.edu
Statement of Interest: None declared.

\section{REFERENCES}

1 Brittenham GM. Iron-chelating therapy for transfusional iron overload. N Engl J Med 2011; 364: 146-156.

2 Adams RJ, McKie VC, Hsu L, et al. Prevention of a first stroke by transfusions in children with sickle cell anemia and abnormal results on transcranial Doppler ultrasonography. $N$ Engl J Med 1998; 339: 5-11.

3 Adams RJ, Brambilla D. Discontinuing prophylactic transfusions used to prevent stroke in sickle cell disease. N Engl J Med 2005; 353: 2769-2778.

4 Adamkiewicz TV, Abboud MR, Paley C, et al. Serum ferritin level changes in children with sickle cell disease on chronic blood transfusion are nonlinear and are associated with iron load and liver injury. Blood 2009; 114: 4632-4638.

5 Inati A, Mussalam KM, Wood JC, et al. Iron overload indices rise linearly with transfusion rate in patients with sickle cell disease. Blood 2010; 115: 2980-2981.

6 Solomon LR. Iron-chelating therapy for transfusional iron overload. N Engl J Med 2011; 364: 1475-1476.

7 Schenk P, Fuhrmann V, Madl C, et al. Hepatopulmonary syndrome: prevalence and predictive value of various cut offs for arterial oxygenation and their clinical consequences. Gut 2002; 51: 853-859.

8 Rodriguez-Roisin R, Krowka M. Hepatopulmonary syndrome: a liver induced lung vascular disorder. N Engl J Med 2008; 358: 2378-2387.

9 Vig R, Machado R. Pulmonary complications of hemoglobinopathies. Chest 2010; 138: 973-983.

10 Degano B, Mittaine M, Herve P, et al. Nitric oxide production by the alveolar compartment of the lungs in cirrhotic patients. Eur Respir J 2009; 34: 138-144.

\title{
A breathtaking reverse bungee jump
}

\section{To the Editors:}

Bungee jumping became popular in the early 1980s. Owing to the prevailing professionalism in the field, accidents are extremely rare. However, occasional medical complications do occur. They are mostly ophthalmologic, but spinal and vascular lesions have been reported [1]. Respiratory complications have also been described (one case of pulmonary haemorrhage [2] and one case of bilateral pneumothoraces in a patient at risk [3]). Reverse bungee jumping is an increasingly widespread fairground attraction during which a one- or twoperson passenger cradle is hurled vertically up to $80 \mathrm{~m}$ into the air by the sudden release of previously stretched elastic ropes (fig. 1). Exceptional accidents have been reported (one case of subdural haematoma [4] and one case of pneumothorax [5]). We describe a case of acute hemidiaphragmatic elevation with diaphragm weakness possibly linked to this activity.

A 52-yr-old office worker $(175 \mathrm{~cm} ; 97 \mathrm{~kg}$; body mass index $31.7 \mathrm{~kg} \cdot \mathrm{m}^{-2}$ ) was referred to our outpatient clinic in May 2006 to investigate recent-onset exercise dyspnoea (self-characterised as "hindering usual acrobatic dance performances"). The patient also reported mild orthopnoea. He did not smoke and had no history of chronic disease, previous surgery or traumatism. Clinical examination was unremarkable. Chest radiography showed an elevated right hemidiaphragm (fig. 2a) capped by passive atelectasis. Thoracic computed tomography did not show other abnormalities. Blood chemistry and blood cell counts were normal. Vital capacity was $87 \%$ predicted, falling to $73 \%$ pred in the supine position. Sniff nasal inspiratory pressure was $57 \%$ pred $\left(64 \mathrm{cmH}_{2} \mathrm{O}\right)$. Cervical magnetic stimulation of the phrenic nerves showed electromyographic responses with normal latencies on both sides (right: $6 \mathrm{~ms}$; left: $6.3 \mathrm{~ms}$; expected values between 5.5 and $6.5 \mathrm{~ms}$ ) but diminished amplitude on the right side (right-toleft ratio 0.5$)$. The corresponding diaphragm twitch oesophageal pressure was low, at $4.7 \mathrm{cmH}_{2} \mathrm{O}$ (expected value $>11 \mathrm{cmH}_{2} \mathrm{O}$ ), and so was the twitch transdiaphragmatic pressure, at $10.9 \mathrm{cmH}_{2} \mathrm{O}$ (expected value $>20 \mathrm{cmH}_{2} \mathrm{O}$ ). 


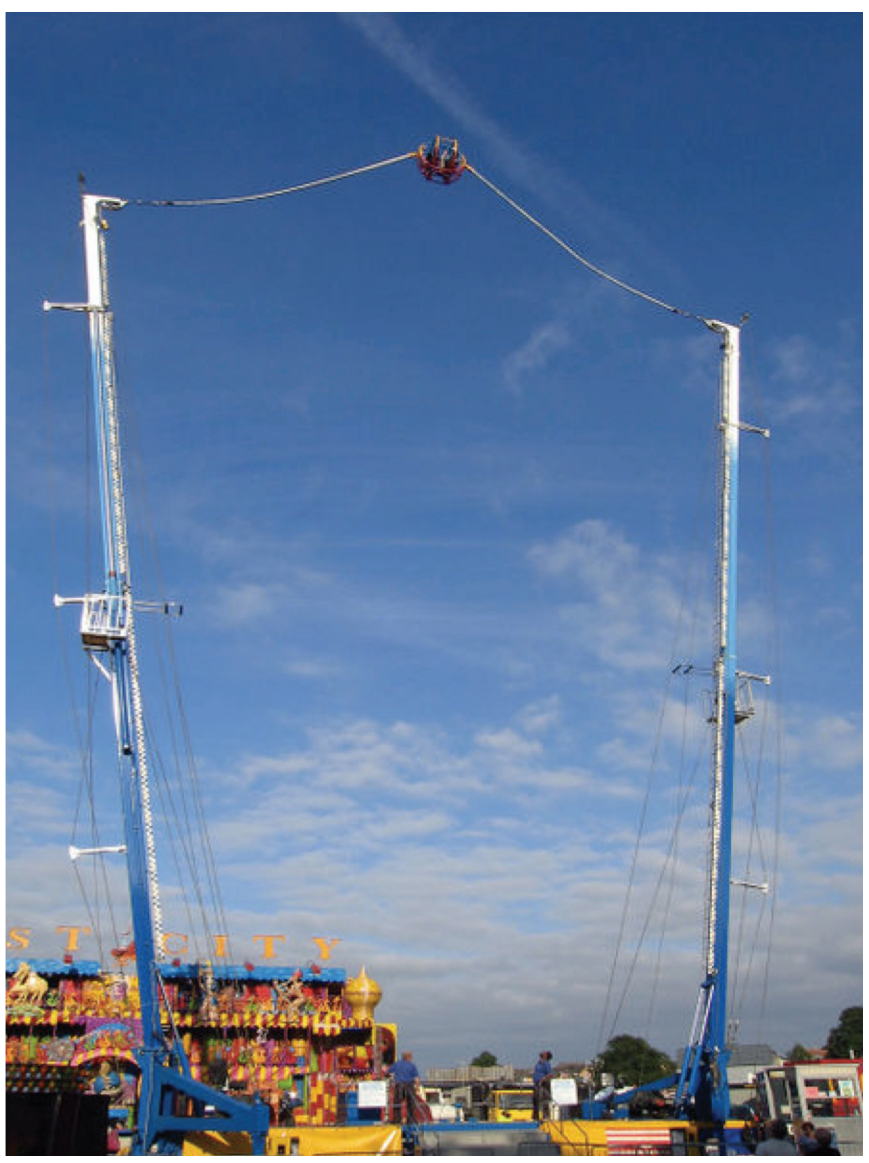

FIGURE 1. A typical reverse bungee jump attraction. Image courtesy of Andrew Dunn.

Thoracic computed tomography showed the absence of diaphragmatic rupture (fig. 2 b). Notably, it also showed multiple images suggestive of hepatic haemangiomas, the largest of which was $11 \mathrm{~cm}$ in diameter. There was no history of shoulder pain, no electromyographic abnormalities in the shoulder muscles and no signs of cervical arthrosis on cervical radiography. A diagnosis of diaphragmatic "eventration" without phrenic nerve lesion was made. Further discussion with the patient revealed that he was able to pin-point the beginning of his respiratory problems. He dated them from a day spent in a theme park a few weeks before, and clearly remembered having felt most unwell, with abdominal pain and a feeling of suffocation, immediately after a reverse bungee jump. We explained to the patient that a diaphragm plication could alleviate his symptoms, but that delayed recovery was not impossible [6]. He chose not have surgery. Over the next 18 months, the symptoms progressively receded, the patient finally reporting being back to his initial form. Repeated pulmonary function tests showed a recovery of vital capacity (91\% pred in October 2007, with no supine fall). Chest radiography showed a progressive return of the right hemidiaphragm to a roughly normal position (fig. 2c). The patient declined repeated phrenic stimulation. He was lost to followup after October 2007. The patient had been informed at the time of initial investigations that his data could be used for scientific purposes and had agreed to this in writing.

Medical complications from roller coasters and other funfair attractions are exceedingly rare. However, submitting large populations of untrained and unselected persons to violent physical constraints is bound to reveal otherwise silent abnormalities, hence the importance of cautionary notices warning people with or at risk of specified medical conditions. It is also important to identify and describe proven or strongly suspected complications for future reference.

In our patient, one possible mechanism to explain the unilateral hemidiaphragm elevation would be a phrenic nerve stretch lesion resulting from a sudden neck movement. Such lesions have been described after chiropractic manipulation of the neck or as a result of "whiplash" in the context of a motorcycle accident [7]. One then expects the diaphragm response to phrenic nerve stimulation, if not abolished, to be
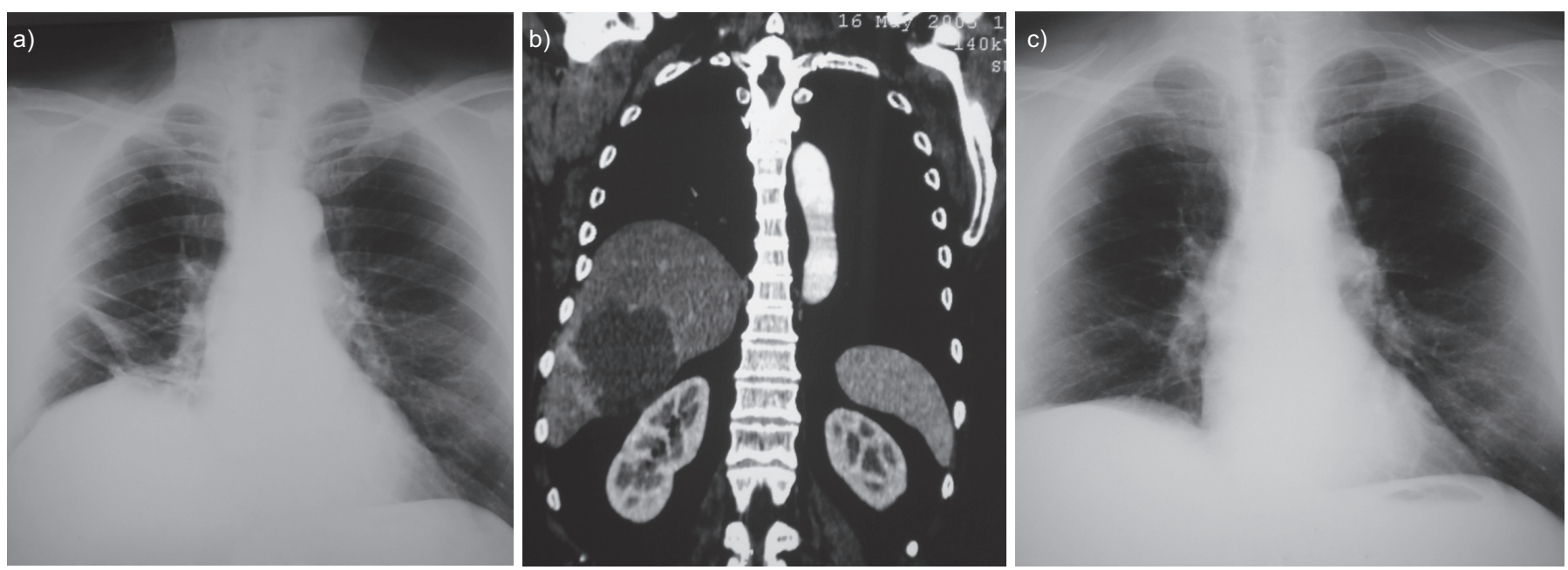

FIGURE 2. a) Initial chest radiograph, taken on May 11, 2005. b) Coronal computed tomography image contemporary with the initial investigations; note the presence of a hepatic mass, classified as one of several probable haemangiomas after contrast imaging and ultrasounds. c) Follow-up chest radiograph taken on October 2, 2007, at a time when the patient no longer complained of dyspnoea; the right hemidiaphragm is still slightly elevated, but recovery has clearly occurred. 
both attenuated and delayed [7]. This was not the case in our patient, where phrenic nerve conduction times were normal and symmetrical, in spite of the reduced amplitude of the motor response on the affected side. This amplitude reduction could correspond to moderate axonal loss, but could simply have been due to the hemidiaphragm elevation modifying the spatial relationship between the muscle and the electrodes. Notably, a partial phrenic lesion would easily explain the observed recovery [6]. Another possible mechanism to consider would be a diaphragmatic, rather than phrenic, lesion. Transient upward accelerations have an inspiratory effect on the chest wall, whereas downward accelerations are expiratory [8]. Therefore, during a reverse bungee jump, the respiratory system will be exposed to a brutal shift from an ascent-related inspiratory force, which can reach $4-5 \times g$, to a descent-related expiratory force, the abdominal content being suddenly "projected" in the cephalad direction at the moment of the trajectory reversal. Given the dome-shaped nature of the diaphragm, the corresponding force will be applied uniformly and perpendicularly to all its surfaces if the abdominal content behaves like a Newtonian incompressible fluid, which is a reasonable assumption. Even in the presence of very severe constraints, this should prevent diaphragm damage, as in the case of an egg not cracking when exposed uniformly to extreme pressures. This hypothesis is consistent with the fact that thousands of bungee or reverse bungee jumps, funfair elevator rides, centrifuges, or similar challenges occur daily without causing an epidemic of diaphragm eventrations, and also more generally with the fact that the diaphragm does resist extremely high and sustained abdominal pressures during labour. However, submitted to pressure, an egg breaks if there is a regional weakening of its shell or if the pressure distribution becomes nonuniform. Diaphragmatic rupture in response to a major increase in abdominal pressure could thus reveal a previously unknown diaphragm defect, a mechanism that has been proposed to explain the exceptional occurrences of labourrelated diaphragm ruptures $[9,10]$. The diaphragm can also give way to a nonuniform rise in abdominal pressure, as in the case of near-side motor vehicle accidents [11]. In our patient, the heterogeneous nature of the haemangiomatous liver could have been responsible for such a mechanism. Of note, no diaphragm rupture was documented. Diaphragmatic "elongation" (strainor sprain-like) was thus more likely and would also be consistent with the observed spontaneous recovery.

Whichever of the suspected mechanisms was actually involved, this observation is a reminder that it is important to look carefully for both cervical and abdominothoracic traumatisms, even in the distant past, when investigating the nature of a hemidiaphragm elevation.
Jesus Gonzalez-Bermejo*,\#, Christian Straus ${ }^{\#, \oplus}$ and Thomas Similowski*,\#

*Service de Pneumologie et Réanimation Médicale, "Service Central d'Explorations Fonctionnelles Respiratoires, Assistance Publique - Hôpitaux de Paris, Groupe Hospitalier Pitié-Salpêtrière, and " Université Paris 6, ER 10 UPMC, Paris, France.

Correspondence: T. Similowski, Service de Pneumologie et Réanimation, Groupe Hospitalier Pitié-Salpêtrière , 47-83 Bd de l'Hôpital, 75651 Paris Cedex 13, France. E-mail: thomas. similowski@psl.ap-hop-paris.fr

Support Statement: The study was supported by Association pour le Développement et l'Organisation de la Recherche en Pneumologie (Paris, France).

Statement of Interest: None declared.

\section{REFERENCES}

1 Zhou W, Huynh TT, Kougias P, et al. Traumatic carotid artery dissection caused by bungee jumping. J Vasc Surg 2007; 46: 1044-1046.

2 Manos D, Hamer O, Muller NL. Pulmonary hemorrhage resulting from bungee jumping. J Thorac Imaging 2007; 22: 358-359.

3 Murphy D, O'Mahony M, Logan P, et al. Bilateral pneumothoraces following a bungee jump in a patient with cystic fibrosis. Respiration 2006; 73: 113.

4 FitzGerald JJ, Bassi S, White BD. A subdural haematoma following "reverse" bungee jumping. Br J Neurosurg 2002; 16: 307-308.

5 Pedersen MN, Jensen BN. Pneumothorax efter "omvendt bungee jump". [Pneumothorax after "reversed" bungee jump.]. Ugeskr Laeger 1999; 161: 5547-5548.

6 Gayan-Ramirez G, Gosselin N, Troosters T, et al. Functional recovery of diaphragm paralysis: a long-term follow-up study. Respir Med 2008; 102: 690-698.

7 Merino-Ramirez MA, Juan G, Ramon M, et al. Diaphragmatic paralysis following minor cervical trauma. Muscle Nerve 2007; 36: 267-270.

8 Loring SH, Lee HT, Butler JP. Respiratory effects of transient axial acceleration. J Appl Physiol 2001; 90: 2141-2150.

9 Dave KS, Bekassy SM, Wooler GH, et al. "Spontaneous" rupture of the diaphragm during delivery. Br J Surg 1973; 60: 666-668.

10 Hill R, Heller MB. Diaphragmatic rupture complicating labor. Ann Emerg Med 1996; 27: 522-524.

11 Reiff DA, Davis RP, MacLennan PA, et al. The association between body mass index and diaphragm injury among motor vehicle collision occupants. J Trauma 2004; 57: 1324-1328.

DOI: $10.1183 / 09031936.00205311$ 